\title{
Mechanism of mitral regurgitation in hypertrophic obstructive cardiomyopathy ${ }^{\star}$
}

\author{
R. B. Pridie† and C. M. Oakley \\ From the Department of Diagnostic Radiology, The London Hospital, London E.1, and the \\ Department of Medicine (Clinical Cardiology), Royal Postgraduate Medical School, London W.12
}

Echocardiography of the mitral valve in patients with hypertrophic obstructive cardiomyopathy has revealed an abnormal pattern of movement. The abnormality is characteristic, readily recognized, and can be explained in anatomical and physiological terms. It consists of a sharp reopening of the valve during systole when it should normally remain in the fully closed position. This abnormal movement mirrors the mid-systolic onset of both outflow tract obstruction and mitral regurgitation. It was only absent in the two patients with the disease in whom both mitral regurgitation and outflow tract obstruction were also absent. A second and less striking abnormality was a reduced diastolic closure similar to that seen in mitral stenosis and attributed to slow left ventricular filling. The echo from the septum is also unduly prominent.

Mitral regurgitation is commonly present in patients with hypertrophic obstructive cardiomyopathy. It is rarely great in volume and is not pansystolic. Consequently, it may be missed or attributed to artefact on the left ventricular angiogram, especially if this is not carried out by a cine technique. Though an occasional patient may have marked mitral reflux with little or no left ventricular outflow gradient, and rare patients with gross outflow gradients may have no mitral reflux, a direct correlation between the height of the gradient and the amount of reflux exists for an individual patient (Rackley, Whalen, and McIntosh, 1966; Wigle, Marquis, and Auger, 1967). The amount of left ventricular outflow tract obstruction is variable, increasing in situations where the systolic size of the left ventricular cavity is reduced (Shah, Amarasingham, and Oakley, 1965). This interdependence suggests that abnormality of mitral valve movement may play a fundamental role in the haemodynamics of hypertrophic obstructive cardiomyopathy (Oakley et al., 1967). In order to elucidate the mechanism of dysfunction, the movements of the mitral valve in these patients have been studied by ultrasound echocardiography.

Received 4 August 1969.

* Based on a paper given to the British Cardiac Society on 5 December 1968.

† Supported by a grant from the British Heart Foundation.

\section{Clinical material}

Sixteen patients with hypertrophic obstructive cardiomyopathy have been studied. Their details are summarized in the Table which includes the gradient between the apex of the left ventricle and the outflow tract. The degree of muscle hypertrophy was assessed from the angiogram, and this too has been recorded in the Table. In all but one of the patients the diagnosis had boen confirmed by catheterization and angiographic studies. The one patient not so catheterized (P.O.) had unequivocal clinical evidence of the disease

TABLE

\begin{tabular}{|c|c|c|c|c|c|}
\hline \multirow{2}{*}{\multicolumn{2}{|c|}{$\begin{array}{l}\text { Patient, } \\
\text { sex, and } \\
\text { age }\end{array}$}} & \multirow{2}{*}{$\begin{array}{l}\text { Gradient } \\
(\mathrm{mm} . \mathrm{Hg})\end{array}$} & \multicolumn{2}{|l|}{ Angiogram } & \multirow{2}{*}{$\begin{array}{l}\text { Ultrasound } \\
\text { echocardiogram } \\
\text { abnormal } \\
\text { opening }\end{array}$} \\
\hline & & & Hypertrophy & Reflux & \\
\hline A.B. & (S) $M_{45}$ & 100 & +++ & ++ & ++ \\
\hline A.F. & (S) $M$ Is & 104 & ++ & ++ & ++ \\
\hline C.G. & (S) F 59 & 67 & ++ & ++ & ++ \\
\hline S.K. & (S) F 22 & 0 & + & + & $\begin{array}{l}+t \\
t+\end{array}$ \\
\hline $\begin{array}{l}\text { C.H. } \\
\text { D.w. }\end{array}$ & $\begin{array}{lll}\text { (S) F } & 19 \\
\text { (S) F } & 26\end{array}$ & $\begin{array}{l}54 \\
60\end{array}$ & $\begin{array}{r}++ \\
+++\end{array}$ & $\begin{array}{r}+ \\
++\end{array}$ & $\begin{array}{l}++ \\
++\end{array}$ \\
\hline C.H. & (S) F 43 & 0 & $\begin{array}{r}T+1 \\
+\end{array}$ & ++ & ++ \\
\hline E.T. & (S) F 47 & 60 & $+t+$ & + & ++ \\
\hline A.H. & (S) M 35 & 50 & ++ & + & + \\
\hline D.P.C. & (S) $\mathrm{F} \quad 17$ & 0 & ++ & 0 & + \\
\hline H.C. & (F) $\mathrm{F} I 9$ & o & ++ & + & ++ \\
\hline P.O. & (F) $F 2 I$ & $?$ & $?$ & $?$ & + \\
\hline E.N. & (F) $\mathrm{F} \quad 13$ & 0 & + & + & + \\
\hline S.J. & (F) F 7 & 20 & +++ & + & ++ \\
\hline J.M.* & (S) M $6 \mathrm{I}$ & 0 & & o & 0 \\
\hline C.B. * & (S) $M 28$ & $?$ & +++ & $?$ & +++ \\
\hline
\end{tabular}

* Post-operative.

(S) Sporadic cases, (F) familial incidence of hypertrophic obstructive cardiomyopathy proved or probable. 
and was one of five affected sibs, in three of whom the diagnosis had already been proved at necropsy or operation. Two other patients also had a family history of hypertrophic obstructive cardiomyopathy.

In two patients ultrasonic studies were carried out post-operatively, one immediately after operation (C.B.) and the other (J.M.) seven years after ventriculomyotomy when he no longer had any clinical evidence of mitral regurgitation.

Two sisters of one patient with proven hypertrophic obstructive cardiomyopathy and a family history of the disease were studied. In these two girls, neither the clinical examination nor haemodynamic and angiographic findings revealed unequivocal evidence of the disorder.

\section{Technique}

Ultrasonic waves are produced by applying pulses of electricity to a piezoelectric transducer suitably placed on the praecordium. Some of the waves strike the anterior cusp of the mitral valve vertically and are reflected back along the same pathway. On arrival back at the transducer, the reflected waves generate secondary electric currents. After suitable amplification, the two pulses deflect an oscilloscope spot enabling the distance of the reflecting surface from the transducer to be recorded either directly by means of a polaroid camera or by feeding the impulses through an inkspray recorder, as described previously (Pridie and Turnbull, I968).

The equipment used in this study was an Eskoline 20 ultrasonic machine ${ }^{1}$ fitted with a Shackman Polaroid camera. Recordings were also made on a Mingograf ${ }^{2}$.

\section{Results}

Normal mitral valve movement In each cardiac cycle, in addition to the opening and closing movements due to ventricular relaxation and contraction, there is another closing and a second opening movement during ventricular diastole (Fig. I). The mitral valve normally closes at the beginning of systole and remains closed until early diastole. Opening of the mitral valve in diastole is followed almost instantaneously by pressure equalization between the left atrium and the left ventricle. As soon as pressure equalization occurs, the cusp returns to its neutral position, which with the ventricle filled is semiclosed. The valve adopts the semi-closed position after cessation of rapid inflow and stays in this position until atrial systole causes further flow through the mitral valve and forces the cusps apart transiently. After atrial systole the valve cusps return to their intermediate position, but the onset of ventricular systole then causes the valve to close fully without any pause being discernible 1 Manufactured by Smith-Kline Instruments I.td. 2 Manufactured by Elamquist.

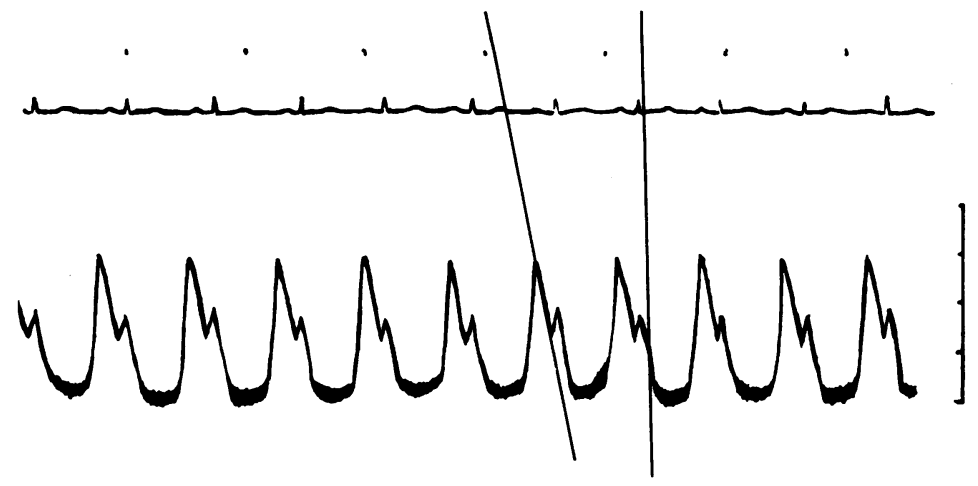

FIG. ${ }^{1} \quad$ Ultrasound record of a normal mitral valve. Vertical line: systolic closure $0.05 \mathrm{sec}$. after the $q$ of the electrocardiogram. Sloping line: initial closure rate $90 \mathrm{~mm} . / \mathrm{sec}$.

unless the PR interval is prolonged. The echocardiogram obtained from patients with various other types of mitral regurgitation will first be shown for comparison with the records for patients with hypertrophic obstructive cardiomyopathy.

Mitral regurgitation This occurs in a variety of conditions.

\section{Rheumatic mitral valve disease}

In rheumatic mitral valve disease, three patterns of movement are seen. First (Fig. 2), when the reflux is slight in association with a stenotic thickened valve which moves poorly, pressure equalization does not occur when the mitral valve opens, so blood continues to pass from atrium to ventricle throughout the whole of diastole, and the valve remains fully open until after the onset of ventricular systole. The ventricle fills slowly so does not distend rapidly and so the valve does nct return to the midway position in diastole. Closure occurs late, but distortion of the

${ }^{1}$ Fig. I to 9 inclusive depict ultrasound records and the conventions are the same in each figure. Downward movements of the trace indicate closing movements of the anterior mitral cusp, and upward movements of the trace indicate opening movements of this cusp. A simultaneously recorded electrocardiogram provides a reference time marker.

The time scale is marked in dots at I sec. intervals on the horizontal axis.

The excursion of the anterior cusp is measured from the vertical scale which is marked at $1 \mathrm{~cm}$. intervals.

Vertical lines have been drawn on the records to indicate the timing of systolic closure of the valve in relation to the onset of electrical systole as shown by the qRS.

Oblique lines have been drawn on the records to indicate the speed of initial valve closure which can be calculated from the slope of these lines in millimetres per second. 


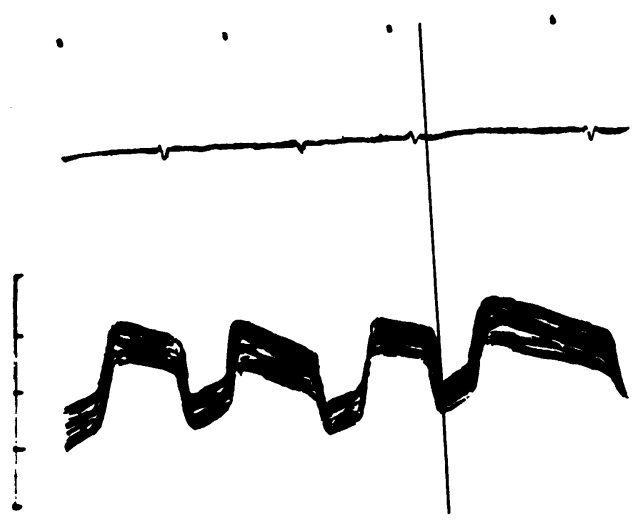

FIG. 2 Ultrasound cardiogram from a patient with tight mitral stenosis, a thick immobile valve, and atrial fibrillation.

Systolic closure is delayed until $0.16 \mathrm{sec}$. after the onset of the $q R S$.

cusps and shortening of chordae prevent their proper apposition so reflux occurs.

The second appearance is seen when there is no stenosis but pure mitral regurgitation. In such cases (Fig. 3) the high left atrial pressure and volume which develops at the end of ventricular systole is followed by very rapid passage of blood from atrium to ventricle. The ventricle distends abnormally fast and the anterior cusp returns to its midposition earlier than usual.

The third appearance occurs with mixed stenosis and regurgitation (Fig. 4). When the initial rapid movement of blood due to the high left atrial pressure and volume has slowed, the stenosis delays complete pressure equalization and keeps the valve open so the trace is 'biphasic'.

FIG. 3 Ultrasound cardiogram from a patient with pure mitral regurgitation with a rapid initial closure rate of over $200 \mathrm{~mm}$./ sec. Compare with Fig. I.

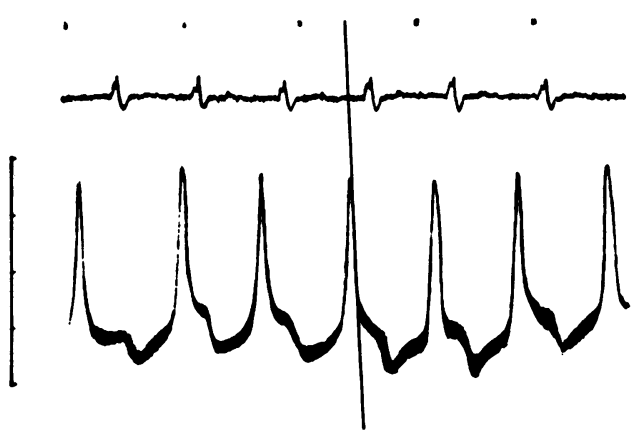

1

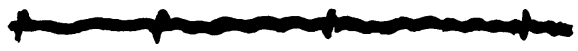

$f$

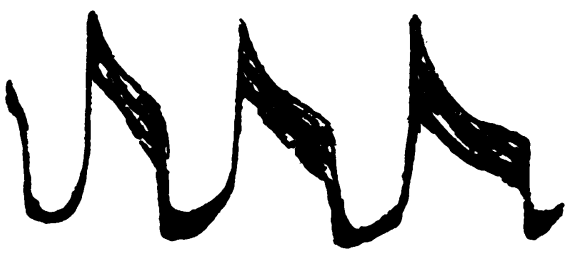

FIG. 4 Ultrasound cardiogram in mixed mitral stenosis and regurgitation when the valve closure starts rapidly and then becomes slower.

\section{Non-rheumatic mitral regurgitation}

In mitral regurgitation due to ruptured chordae tendineae, an exaggerated rate of mitral valve closure occurs just as in pure rheumatic mitral regurgitation, but, in addition, the excursion of the valve cusp is greater than normal (Fig. 5). In most cases this exceeds $3.5 \mathrm{~cm}$.

FIG. 5 Ultrasound cardiogram from a patient with ruptured chordae tendineae showing an abnormally rapid initial closing movement and a very large excursion.

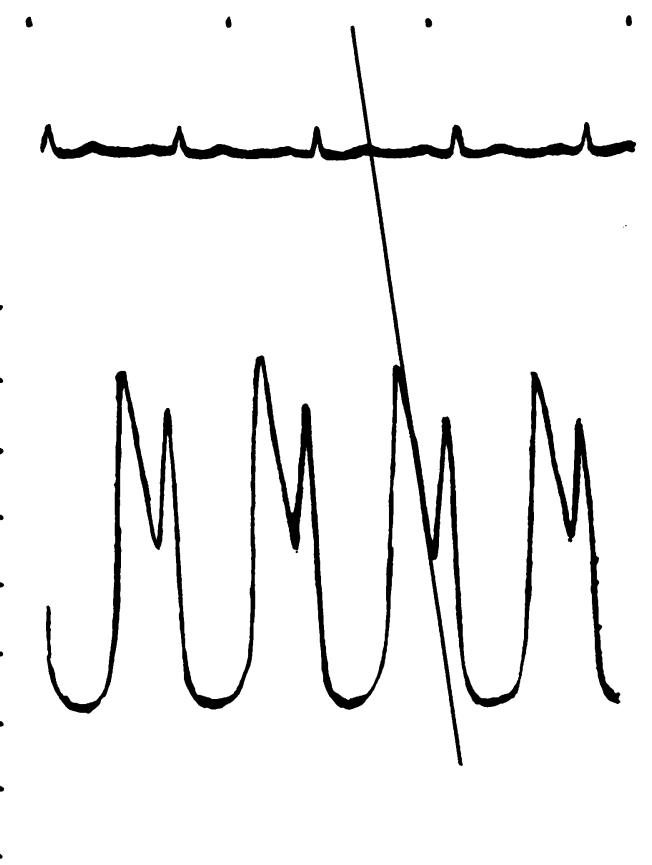



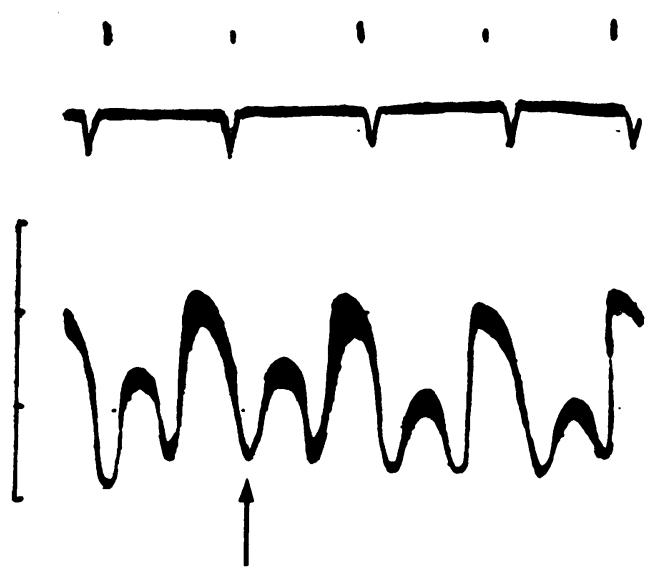

FIG. 6 Ultrasound cardiogram from a patient with hypertrophic obstructive cardiomyopathy in which the mitral valve opens to the midway in systole but closes again before diastole. The start of the abnormal opening movement is arrowed.

\section{Hypertrophic obstructive cardiomyopathy}

All the patients, except the one who had no clinical evidence of persisting cardiac abnormality after operation, showed an abnormal opening movement of the mitral valve in systole. The pattern of this abnormal movement varied somewhat between patients.

The most florid opening movement illustrated in Fig. 6 was seen in a 15-year-old Egyptian boy. After closing normally at the start of systole, the valve began to open again almost immediately, moving forward into the semi-open position. Before the completion of systole, the anterior cusp moved backward into the fully closed position and then opened normally in diastole.

Most of the patients did not show this complete mitral valve reopening and reclosure in systole which is marked +++ in the Table. In the majority, reclosure after abnormal opening was only partial at the end of systole, being interrupted by the normal diastole opening movement associated with ventricular relaxation (Fig. 7). Those showing this pattern are marked ++ in the Table.

Two patients (P.O. and E.N.) only showed the abnormality of movement after provocation with amyl nitrite. This response shown by + in the Table is illustrated in Fig. 8. No abnormal systolic opening occurs in the left-hand trace, but systole reopening is present in the right-hand scan which was done after amyl nitrite. These patients also showed a change in the mid-diastolic closure rate of the mitral valve which became slower

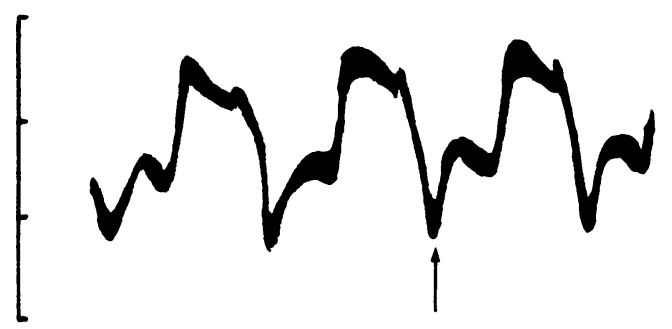

FIG. 7 Ultrasound cardiogram from a patient with hypertrophic obstructive cardiomyopathy. The valve reopens in systole to the mid position (arrowed) but closes only slightly before diastolic opening.

after amyl nitrite. This slow return of the cusp to the midway position was seen in several of the patients, and is illustrated in Fig. 7 and 8, where the valve remains widely open throughout the short diastole.

The sisters of the child with familial hypertrophic obstructive cardiomyopathy (E.N.) were aged 9 and Io (Fig. 9). Both showed a forward movement of the mitral valve cusp in systole, but neither showed any tendency to reclosure at the time of isometric ventricular relaxation just before the valve opens. However, the forward movement of the cusp is conspicuous and reaches as far as the mid-position which is achieved after atrioventricular pressure equalization in diastole. This is suggestive of an abnormal systolic movement of the cusp.

FIG. 8 Ultrasound cardiograms from a patient (A.H.) with hypertrophic obstructive cardiomyopathy taken before (left) and after amyl nitrite when a systolic opening movement occurs (arrow).

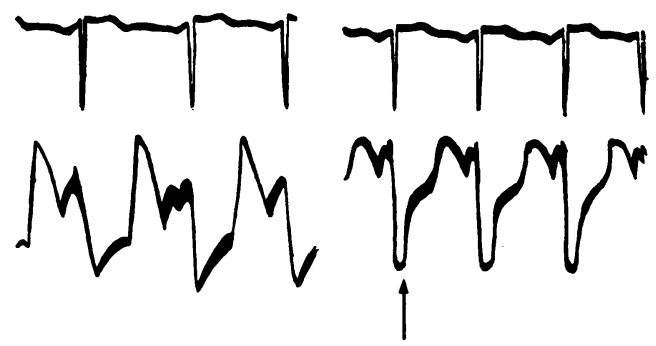




\section{Discussion}

The systolic opening of the mitral valve can be explained on anatomical grounds. Fig. Io depicts a longitudinal section through the left ventricle and shows that the anterior cusp of the mitral valve can only come into apposition with the posterior cusp to produce valve closure when the chordae tendineae and papillary muscles are slack. Should the papillary muscles contract prematurely or excessively, the aortic cusp of the valve could be pulled forward into the outflow tract of the left ventricle and so allow regurgitation of blood from the left ventricle to the left atrium. Such an abnormal papillary muscle action with consequent forward movement of the aortic cusp of the valve would explain both the reflux and the left ventricular outflow tract obstruction. On this hypothesis it is also to be expected that the outflow obstruction will vary directly with the amount of mitral regurgitation, as has already been shown by Wigle and his colleagues (1967).

It is interesting that the systolic reopening of the valve is only to the mid-position and not to the fully open position. Tension from contracted papillary muscles cannot open the valve completely. The fully open position can only be achieved when the ventricle is empty in early diastole and the relaxed papillary muscles allow the subvalvar supports to bow forwards. Similarly, full closure can only be achieved when the cusp, chordae, and papillary muscles are bowed backwards in the contracting ventricle (Fig. ro).

A slightly similar but less obvious systolic forward movement of the valve is sometimes seen in patients without hypertrophic obstructive cardiomyopathy. Though similar, the movement is not identical, as it is gradual rather than abrupt. This pattern is like that seen in the pre-amyl nitrite trace in Fig. 8. The sisters of the girl with proven familial hypertrophic obstructive cardiomyopathy shared this forward movement in systole (Fig. 9) which is often seen in patients with increased left ventricular stroke volume and is usually ascribed to movement of the valve ring. It is frequently seen in patients with aortic or mitral regurgitation. The forward systolic movement in hypertrophic obstructive cardiomyopathy differs from this ring movement by the change of direction towards closure in protodiastole.

Augmentation of both the mitral regurgitation, the left ventricular outflow tract obstruction, and the abnormal valve movement by amyl nitrite gives support to their

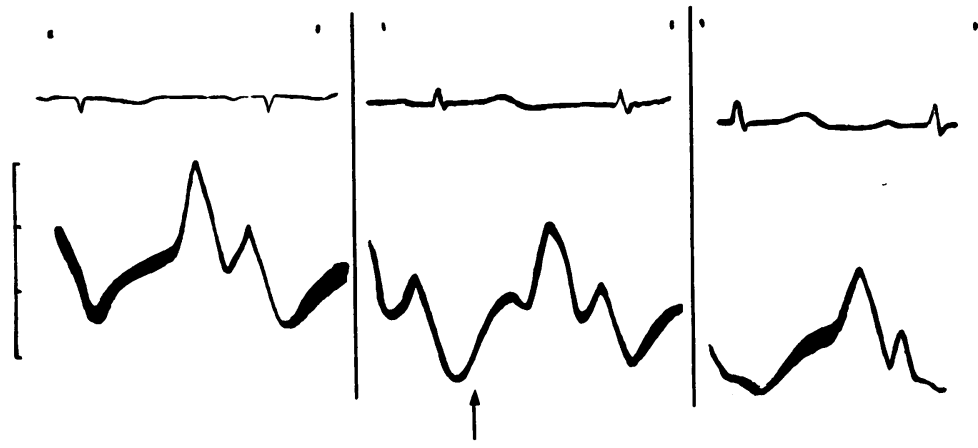

FIG. 9 Mitral valve movements of three sisters. The centre record is from the sister with proven hypertrophic obstructive cardiomyopathy. The abnormal opening movement is arrowed.

common mode of origin. It is possible that the other two of the three sisters whose valve movements are shown in Fig. 9 might have shown more definitely abnormal systolic movements had they been retested after amyl nitrite.

The absence of the normal rapid return of the anterior cusp from the fully open to the semiclosed position in diastole can also be explained by muscular dysfunction. This

FIG. Io Diagrammatic section of the heart through the left atrium and ventricle, anterior cusp of mitral valve, interventricular septum, left atrium, left ventricle, posterior cusp of mitral valve, papillary muscle, right atrium, right ventricle. This shows the position of the heart and anterior cusp as they are in a patient lying supine for ultrasound recording. $L V$ left ventricle, $L A$ left atrium, Ao aorta, $A C$ anterior cusp of mitral valve, $P C$ posterior cusp of mitral valve, PM papillary muscle, IVS interventricular septum, $R V$ right ventricle, $R A$ right atrium.

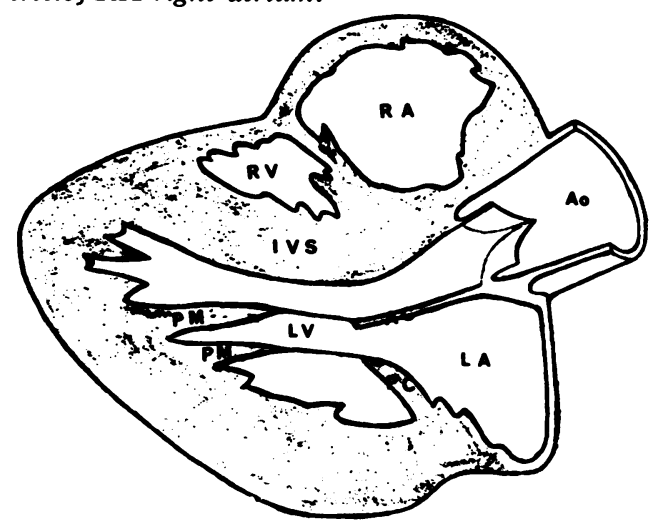


movement is dependent upon rapid distension of the left ventricle producing tension in the chordae tendineae and closing the valve. The compliance of the ventricle in hypertrophic obstructive cardiomyopathy is reduced (Braunwald et al., I960; Cohen et al., 1964). Hence, ventricular distension and filling occur only slowly and the diastolic movement of the anterior cusp is similar to that seen in mitral stenosis but for a different reason. The echocardiogram in severe left ventricular hypertrophy from hypertrophic obstructive cardiomyopathy or aortic stenosis can closely resemble that from a patient with mitral stenosis with cusp thickening, but delayed initial systolic closure is not seen.

The authors are indebted to Professor John Goodwin, Royal Postgraduate Medical School, and Dr. Wallace Brigden, The London Hospital, for kindly making their patients available for study. The work of Mr. Ruddock of the Photographic Department at The London Hospital is gratefully acknowledged.

\section{References}

Braunwald, E., Morrow, A. G., Cornell, W. P., Aygen, M. M., and Hisbish, T. F. (1960). Idiopathic hypertrophic subaortic stenosis. American fournal of Medicine, 29, 924.

Cohen, J., Effat, H., Goodwin, J. F., Oakley, C. M., and Steiner, R. E. (1964). Hypertrophic obstructive cardiomyopathy. British Heart fournal, 26, I6.

Oakley, C. M., Raftery, E. B., Brockington, I. F., Steiner, R. E., and Goodwin, J. F. (1967). Relation of hypertrophic obstructive cardiomyopathy to subvalvar mitral incompetence. In Proceedings of the British Cardiac Society. British Heart fournal, 29, 629.

Pridie, R. B., and Turnbull, T. A. (1968). Diagnosis of pericardial effusion by ultrasound. British Medical fournal, 3, 356.

Rackley, C. E., Whalen, R. E., and McIntosh, H. D. (1966). Ventricular volume studies in a patient with hypertrophic subaortic stenosis. Circulation, 34, 579.

Shah, P. M., Amarasingham, R., and Oakley, C. M. (1965). Haemodynamic effects of changes in blood volume in hypertrophic obstructive cardiomyopathy. British Heart fournal, 27, 83.

Wigle, E. D., Marquis, Y., and Auger, P. (1967). Pharmacodynamics of mitral insufficiency and muscular subaortic stenosis. Canadian Medical Association fournal, 97, 299. 